\title{
An Analysis of the Transition from Scenic Designer for Theater to Themed Entertainment Designer
}

\author{
Rachel Rauscher \\ Atlanta, GA \\ Bachelors of Arts in Theater Studies, Emory University, 2013 \\ A Thesis presented to the Graduate Faculty \\ Of the University of Virginia in Candidacy for the Degree of \\ Master of Fine Arts \\ Department of Drama
}

University of Virginia

May, 2016 


\section{Preface}

One of the struggles facing a scenic designer is how far past the role of "scenic designer for theater” their skills can stretch. There are many professions that have similarities to the profession of scenic design, which allows for a natural transition if a designer wants to expand beyond designing for theater. One of these professions is as a Themed Entertainment designer. Scenic Design for theater and Themed Entertainment design share many similarities in their skillset.

It has been said that film is a director's medium, and theater is a writer's medium, but themed entertainment is a designer's medium, in terms of what drives the design. To analyze this idea I conducted interviews with several designers that have transitioned from theatrical designer to different areas of themed entertainment design, to conclude from their experiences and anecdotes whether a transition from theater to themed entertainment is realistic or even desirable for a scenic designer.

To analyze this topic, it was important to review different areas of themed design, and describe the full design process for each designer, in both their current jobs in themed entertainment, as well as their process in designing for theater. I will discuss topics relating to training, personal skillsets, necessary tools, employee provisions, research guidelines, and changes to design approach, as well as logistical concerns such as budget, time frame, hierarchy, and level of involvement in construction. I will show that a trained scenic designer can successfully transition to working as a themed entertainment designer. 


\section{Table of Contents}

Chapter 1: Career Beginnings 1

Chapter 2: Necessary Tools $\quad 5$

Chapter 3: Employer Provisions 11

Chapter 4: Large Scale Design Considerations 13

Chapter 5: Objectives for Audience Effect 16

Chapter 6: Designer’s Primary Focus: Aesthetics versus Construction 18

Chapter 7: Observational versus Immersive Environments 21

Chapter 8: Research and Flexibility in Concept 25

Chapter 9: Collaboration and Hierarchy 29

Chapter 10: Presentation of Design Concepts 34

Chapter 11: Moving Forward after a Design Concept is Accepted 36

Chapter 12: Budget Considerations 40

Chapter 13: Timeframe Considerations 43

Conclusion $\quad 46$

$\begin{array}{ll}\text { Works Cited } & 48\end{array}$ 


\section{Chapter 1}

\section{Career Beginnings}

How does a scenic designer transition to themed entertainment design, and how is it possible to break into the field? What training is necessary, and how does one present himself to the industry in order to find work? Is there a similarity to how one breaks into theater? There are many paths that a designer can take in order to enter theater industry. There is no specific level of education required, though there is much variation in expectation of different theater producing organizations; typically a designer's portfolio will be the most important item used to illustrate their skills as a designer. Many begin designing through working in a related field, such as carpentry and technical direction, or scenic painting, as the fields are closely related in subject matter; a varied skillset in multiple disciplines can help a designer to become well-rounded, and be able to communicate a designer's vision more clearly to the production staff. Although it may not be necessary for a designer to have a higher education degree in order to become successful, it is important that there is proper training, which is more clearly covered in a specific BFA or MFA program, rather than being self-taught or learning through working in the industry. While neither of these academic degrees are required to become a designer, the training and study provided is essential. I spoke to several designers who began working in theater, and have since transitioned into different types of themed entertainment design. Each presents a different experience in their day-to-day proceedings, as well as a different path to get to where they are now.

Batul Rizvi, the current production and entertainment design specialist at Busch Gardens, Williamsburg, received her BFA in Design and Production from the University of North Carolina School of the Arts. Her program gave her practical experience designing and assistant designing, as well as drafting and rendering skills. Along with her work painting and designing for summer stock theaters, her skill set provided her the qualifications necessary for her position at the Busch Gardens theme park.

As the sole entertainment design specialist for Busch Gardens Williamsburg, Rizvi is typically presented with projects based on a design need somewhere in the park. These projects could be anything from designing a kiosk for the Food and Wine Festival, an annual attraction at Busch Gardens, to picking a new color palette for an employee break area. There are many events that are re-mounted annually, such as 'Howl-O-Scream' in autumn and 'Christmastown' in the 
winter, and there are many meetings about potential improvements that could positively influence guests' experiences, and what updates may be necessary year to year. Much of Rizvi's role is designing the updates for existing features and new installations, such as kiosks and signage, based on decisions from those meetings.

Brian Barker, a Virginia based scenic designer who now owns his own design firm, earned his BFA from Virginia Commonwealth University with a concentration in technical direction and set design. He followed his bachelors with an MFA in Set Design from Tennessee, a program heavily based on practical design, which helped him to learn strong rendering and drafting skills while designing four productions over the course of his three-year program. Though some connections could be made through his graduate program, Barker found work out of college by contacting as many theaters' artistic directors as possible.

I'd send an email or make a phone call and request an interview. I'd show my portfolio, talk about how I work. If not immediately, then within a year or so [I'd usually be given a project]. From then, I'd get a response back, and they would usually call and ask if you could design a specific show. But from a commercial work standpoint, you can’t just call Nickelodeon and ask to design something. (Barker)

Though his training is in scenic design for theater, Barker now spends the majority of his time designing for themed entertainment. For commercial work in the themed entertainment industry, Barker is typically contracted by a marketing company that is vying for a bid from the client. The client will often send the project to a handful of marketing companies and ask for proposals, and typically the least expensive bid will win. The company asking for proposals is not interested in dealing with designers, shops, production managers, etc. The marketing firms' proposals will detail the cost of the project, as well as some details about what the design itself will be, and they will take care of the staffing and production details once the bid is accepted. The marketing firms don't have in house designers, so they find a freelance designer who they will pay a design fee, or an hourly rate, depending on the project.

Barker has found much of his commercial work through connections with former professors and a former partner in his design firm. Most of the contracts with marketing companies 
that Barker has been given, he can attribute to word of mouth about his business. A lot of the work Brian gets is dependent on the quote given to the marketing company, and on what proposal was selected by the large company. For some clients, such as with Barker's work with Nickelodeon, the primary goal is to perfectly recreate an installation based on an old TV show, and then manage the build. Some projects will require the designer to act as more of a production manager, and to contract the shop that will be used as well. In order to take contracts with this type of requirement, it has been important for Barker to forge relationships with many scene shops throughout Virginia, and at times, lean on his technical direction training to build structures for his installations himself.

Another designer to cross over from theater to entertainment design is Charlie Otte. Otte earned his BA from the University of Virginia as a Drama and English double major, and went on to experiment in acting, designing, stage managing, and writing, finally to settle on a mix between directing and designing. He worked primarily as a stage manager after graduation, while pursuing other options closer to his desired field. After several years working in theater around the country, Otte moved to Los Angeles in order to earn his MFA from USC Cinematic Arts. Since then, Otte has worked primarily in film and television, often working on some lighting design, but focusing mainly on directing, film making, and working as an artistic director, through freelancing and working with large theme design firms such as ThinkWell, Disney, and the Hettema Group.

During his work with themed entertainment firms, Otte says that clients would approach his firm with an idea of what they are interested in, and the firm would form a proposal. Recently his project with the Smithsonian, a re-design of an exhibit in the museum, has followed this pattern. The creative teams begin with a large brainstorming session that includes the client and ten to fourteen people that include writers, the creative director, a couple designers, visual and graphic artists, and project managers. The team will meet for six to eight hours discussing ideas, while the visual artists are constantly sketching, in order to give a quick visual reference. After the charrette, the client leaves, and the rest of the creative team moves forward with descriptions, artwork, creating a story, generating the actual design and floorplans, pulling research, and determining specifics of what will be created.

Finding a job in theater versus themed entertainment has strong similarities, as they are both grounded in needing to make strong connections, and to put in a lot of effort up front to establish oneself. Peddling your portfolio, and being willing to do smaller jobs, whether that is as a draftsperson at a design firm, or offering to help design or render small units for scene shops, are 
the best ways to get your name out, and begin building a reputation to facilitate relationships with theaters and design firms. 


\section{Chapter 2}

\section{Necessary Tools}

Designing for Theater and Themed Entertainment share similar needs as far as the tools required to successfully get the job done. Both fields share a common language, due to a large portion of designers in themed entertainment coming from a theatrical background. For designers interested in working in themed design, there is a natural transition due to a similarity in skillset. While similar computer programs and artistic skills are used, the focus is different between each field, and the skills needed to make the leap from theater to entertainment may not have been covered thoroughly in a scenic design MFA or BFA program.

As with entertainment design, Theatrical design is moving towards being fully automated, and hand-drafting and rendering is on the decline. It is rare to see a designer use hand drafting to submit their ground plans, elevations, and sections, though the skill is still taught in bachelors and masters programs alike. Hand-made models are incredibly time intensive, and difficult to adjust once completed, which can be problematic in a collaborative business, where a show could be ever-evolving. Because of the speed and precision of computer drafting, programs such as Vectorworks and AutoCAD are the new standard. These programs allow for drafting, building and fully rendering three-dimensional models, as well as creating textures, and using lighting and rendering modes to create as realistic an image as possible. A major adjustment to a design could be made in an hour using Vectorworks, which would take days of adjusting hand drafting and rendering for the same change. Along with the movement toward computer drafting, programs such as Adobe Photoshop and SketchUp are commonly used for digital renderings and digital modeling. This stock of computer programs allow the designer to adjust designs much more quickly and efficiently than with hand rendering techniques. Improved efficiency creates time to work on more projects, and create a greater economic advantage because of the ability to take more work. Though computer rendering is growing in importance, hand rendering in charcoal, watercolor, pastel, and pencil are all used, though more commonly as an additional tool to be used with digital rendering. A series of digital rendering, printing, painting over, scanning, photo-

shopping, and repeating until a desired image is created, is a tactic that can create unique artwork on the way to developing a scenic design. 
While the standards used in scenic design for theater are constantly evolving, it remains that the tools used are generally up to the designer himself. A director can ask for something specific, such as a hand built model, to help visualize blocking. However, the creation of paint elevations (painted or computer animated images that show what the final design will look like, and indicate specific paint treatments and colors), and the way a drafting packet is presented can be unique to the designer, so long as it is clear in intention, and gives enough information to the production team. In themed entertainment design, however, much of what is produced on the designer's end is dictated by what the client would like to see. While a fully rendered digital model has a realistic quality, and can easily be adjusted, often it is more beneficial for the designer to present the client with an "artistic" rendering that better represents a mood or feeling, and is less articulated.

Sometimes clients ask for something much more conceptual that has a much more sketch quality to it. There's an acceptance to it that it isn't looked at as truth. If I do a full blown computer model with lights and treatment, the critique of that is a whole lot higher, and harder to get approval on, because it’s taken as reality. (Barker)

A realistic digital model is a useful tool in describing what will be built, but at early stages in the design process, it could hinder the process rather than incite productive discussion. It can make the client feel locked into the entire view, and make it more difficult to see the small adjustments that could be made to satisfy their vision. Concept art, such as an initial hand drawn color rendering of a Disney character before computer animation takes over, has the ability to start a dialogue by establishing a general mood or tone for an installation, and possibly a few details that would indicate whether an idea is moving in the right direction, without becoming too restrictive too quickly. A fully realized model can create a closed off, more restrictive reaction from the client if brought in too early, because it is a literal representation of what has been discussed. For designers who prefer to work digitally, there are many settings within drafting programs, (such as the vectorworks "sketch rendering" mode, for instance) that can be used to create a more conceptual version of what is being worked on through computer drafting. 
Barker's work is often based on what the marketing company thinks will sell. In his experience, he has never produced a hand built model for a commercial job, and works solely in digital. Another program he finds particularly useful is Cinema 4D, a program used to create three dimensional graphics, to be used for animation and digital rendering. This program, along with Vectorworks and Photoshop, make up the bulk of the tools used for Barker's commercial and scenic designs.

In some cases the client's preferences inform the designer's decision on how to present their design, in others it can be left up to the designer's discretion. Upon beginning her job with Busch Gardens Williamsburg, Batul Rizvi was told that any way she wanted to work would be acceptable, providing that everything was clearly laid out, accurate, and attractive, and that she was able to work efficiently. Even so, her preferred method of creating a design package has changed drastically since she has moved from designing for theater to designing for a theme park.

In theatre, I loved creating paint elevations, tangible models, hand drafting, and having a very analog work studio. I preferred the execution team look at my own brush strokes and the colors I would physically mix. I think that works in theatre because typically - you, your team, and your client(s) are very artistically based people. In theme design, the business side of the coin flips a lot and you have to make your design appeal to a very broad range of people. (Rizvi)

Rizvi explains how she has had to adjust her preferred method of developing a design, now that she works primarily in theme park design.

I work digitally now. For park installations, kiosks, and new buildings - I will 3D model in either SketchUp or Vectorworks and put together a design package with orthographic views from a ground-plan, specific detail views, and a 3D composite view showing how it fits in the park. For more seasonal designs dealing with overlays on the existing park elements, I will typically use Photoshop to clearly identify a before $\&$ after look with a design package detailing dimensions, scale, products, whatever necessary to implement the design. (Rizvi) 
Even though her main method of creating a design packet has adjusted, she still incorporates a more hand-created method into the beginning of all of her works.

Because of my background with analog work and the nature of how I work, I normally just start anything with a pen and paper. I sketch everything before making it digital. Sometimes, if color is a huge part of the design, I'll get a watercolor pad and start just playing with colors to reference when I go digital. (Rizvi)

While many of the programs used in entertainment design are already well known and used frequently in the theatrical community (Vectorworks, SketchUp, Adobe Photoshop, etc.), there are a plethora of computer programs that are not often used for theatrical design applications, but can assist in creating a sophisticated finished product to aid in a theme design. 3DS Max is a program that uses state of the art 3D rendering and texture mapping to create lifelike and detailed animations. Revit is another product from Autodesk, which is targeted more towards architecture and building design and animation. Both of these programs have become a necessary staple for Rizvi in her work for Busch Gardens, due to the sophistication of the final product that can be achieved over SketchUp.

In Charlie Otte's experience with higher profile themed entertainment design, common practice is also moving in a digital direction.

"You used to bring in an easel with some key drawings, floor-plans, so people could get an idea of what things look like. Now you have a 52" monitor with a SketchUp model you can fly through.” (Otte)

At the same time, Otte states that there is a more finished final product needed than what can be provided through SketchUp. This is where high concept artwork comes into play, though it is shifting from being fully hand created to mostly digital. High concept artwork is usually beautiful, skillfully done artwork that shows not only the aesthetic quality of an installation or even of a specific character or scene, but it also evokes the desired effect that the installation should 
have on the audience. This artwork typically starts from a hand drawn pencil sketch, and develops through digital rendering to create the evocative artwork that will inspire a larger installation.

While 3D digital rendering is a shared medium used by designers in both theater and themed design, graphic design is a skill that is rarely touched on in the world of theater, which has proved invaluable in many areas of theme design.

[A skill necessary for entertainment design is] graphics, for sure. [You could find out that] this time we're going to have to print the drop [instead of painting it]. I've spent three to four years teaching myself illustrator and graphic design, because of needing to print a lot of signage, drops, etc. InDesign as well, for invites, photo ops for people to pose with, etc. (Barker)

In Barker's work in the entertainment industry, paint becomes much less of a concern, and printing a logo or backdrop is more cost effective and efficient. This requires a comprehensive knowledge of graphic design in order to get a clean, high quality product. For a stage environment, the focus is on having a perfect aesthetic quality from a distance, because the audience is in a position where they can see the entire stage at once, and has no opportunity to inspect the scenic elements up close. For theme design, the audience is immersed in the environment, viewing each element from different angles, sometimes mere inches away. Any printed image, be it signs directing you towards the queue of the next ride, or a backdrop for a photo op with a beloved TV character, the image must transfer from the computer to the printer without pixilation or change in color quality. Graphic design and print skills are necessary to successfully transition into many areas of theme design.

According to Mr. Otte, all skills used in design for theater are put to use in entertainment design. Though he has yet to see a hand-made model built to help the design process, large hand models are often used for display purposes for theme parks.

Virtually everything seems to come into play. There are probably more media based skills that come into play for corporate work and theme parks. I think you need to have all the scenic design skills from theater, and your artistic skills, in terms of drawing, must be high; also that you can understand CAD, AutoCAD, 
SketchUp, the whole Adobe suite. Everybody kind of uses [the Adobe suite] and works together. Then more elaborate programs, which you'd have to learn at a specific place. There are always new things. As soon as I say 'learn this,' it’s going to change. (Otte)

The tools that are the most prevalent in both design fields are constantly evolving, and it is important to continue learning new techniques and programs as a designer for both theater and themed entertainment. Computer drafting software, digital rendering software, and 3D modeling software are the most important tools used by designers currently, though themed entertainment relies more heavily on graphic design and digital animation in addition. For scenic designers interested in transitioning to entertainment design, hand rendering remains highly important, but adding more sophisticated programs for creating textures, renderings, and high res graphic designs, becomes significantly more important when moving on from theatrical design. 


\section{Chapter 3}

\section{Employer Provisions}

As a designer for theater, it is generally expected that all of the tools necessary to communicate your design are already in your possession. As freelance designers, purchasing programs or subscriptions for programs such as Vectorworks, AutoCAD, the Adobe suite, SketchUp, etc., are all assumed as personal business expenses. There are exceptions, primarily when it comes to university jobs or in-house design jobs, which could provide some of these programs, though it is not an automatic. Much like in theater, tools provided by the employer for entertainment design vary depending on many factors.

For Brian Barker, the client or marketing company that has contacted him does not provide any tools for him to use. As the owner of his company, Barker is responsible for maintaining his collection of computer programs that allow him to complete the various tasks he has taken on. He does have a laptop that he has loaded with standard Vectorworks, which he provides when he takes on an assistant for a project, if they do not already have Vectorworks on their computer, or have an educational version that causes a permanent watermark on all drafting.

Batul Rizvi, the current scenic designer for Busch Gardens Williamsburg, is provided with a fully stocked iMac and external monitor. Her equipment is stocked with SketchUp, Adobe Photoshop, iTunes, LayOut, Meshmixer, and Vectorworks 2013. She also has a PC that runs AutoCAD 2014, and easy access to any hand rendering materials when necessary. Because of her position as an in-house designer, a more specific set of tools is already provided, and all items are worked into the budget. The materials provided are some of the many benefits of working as an in-house theme designer, as well as having a constant influx of work, and a benefits package that includes insurance and a $401 \mathrm{~K}$, benefits not often found for a freelance scenic designer for theater.

Charlie Otte has worked with many corporate themed entertainment design firms around the world, and he indicates that this type of design firm provides the bulk of the necessary programs for their employees.

Thinkwell, for instance, had probably 20, 30, 40 people just drafting on a couple projects. Everyone has a computer station, they were using AutoCAD or vectorworks. Mostly CAD. Everyone had that at hand. They are constantly trying 
to upgrade within reason what they have. Hettema, for instance, doesn't have quite so robust a design department, but they have editing suites, and they show a lot more. ImaginArts had a lot of media equipment, was more film design based, more designers. These are mainly mid-size or larger. (Otte)

Designers interested in hand rendering would be providing their own materials, and most employees have their own laptop and programs that they can use from home, but are not expected to bring in on a daily basis. As a freelancer, Otte will often develop his work at home and bring it in later to pass on to the draftsmen and artist interns.

It is important for designers in both theater and themed entertainment to have access to the tools necessary to be competitive in their chosen fields. It is rare that these computer programs and hand rendering materials will be provided by a client, and is only to be counted on if a designer is working for a design firm that has a standardized way of creating design materials. Even in those cases, it is important that a designer have access to computer drafting, rendering, and animation software prior to working for a design firm, in order to be familiar with current standards. Even so, more advanced design firms sometimes have programs available for use that are more sophisticated, and less prevalent, that must be learned on the job. 


\section{Chapter 4}

\section{Large Scale Design Considerations}

When designing for a play, it is not often that that the architecture of the theater is part of what is being created. There are exceptions when it comes to some outdoor theater and nontraditional theaters that aim to bring theater to new and interesting locations. For more traditional theater set-ups, the scenic designer does not have to design the environment in which the set will live. Architectural elements to be taken into consideration include the existence of a fly system, height of the grid from the deck, the stage configuration (black box, proscenium, thrust, etc.), existence of a projection loft, trap doors, etc. Other considerations are determined based on the production staff and flexibility of the facilities, such as whether rehearsal space and build space is shared, whether building must happen on the actual stage or off-site, crew abilities, and expected build time. The architecture and the production company will certainly put restrictions on what can be designed, and permanent changes to the structure will typically not be approved in order to accommodate a particular design.

Unlike scenic design, theme design can often include building the structure that will house the attraction. From the beginning of a theme park's development, many considerations must be taken. The land must be zoned for appropriate leisure use, and the initial design process must consider the number of visitors expected to circulate through the park and various attractions, the

features displayed, and techniques used to convey information to patrons, whether through graphics or audio. The initial plan must also include information about parking and transportation, space left open with potential for future expansion, and safety and health standards must be identified (Wylson and Wylson, pg. 152). Creative input starts at the beginning, though it can be broadly related to the general theme of the park:

"The creative input will vary from securing the authenticity of a fantasy world, to the restructured landscaping in a zoo that provides a sympathetic environment for the animals.” (Wylson and Wylson, pg. 152)

A general layout including the footprint of rides and attractions are necessary in the initial planning process, as well as a clear route of moving people through the park and queues. It is 
necessary to avoid cul-de-sacs and bottlenecks, and keep routes wide enough to allow for a constant stream of people. Routes within the park should be fully divided from queues for attractions, so prevent confusion and impeding the flow of traffic. (Wylson and Wylson, pg. 153)

A theme park should strive to keep the audience from feeling any sense of confusion or frustration, which necessitates an early consideration of a house-style to create cohesion around the park, and frequent and consistent signage to direct patrons through the park. Graphics and signage convey information, but they also give a more directed character to the park. It is also important to consider whether the location of the theme park will attract an international audience. Signage should consistently be available in as many languages as necessary to suit the patronage expected, complete with symbols and graphics to clarify meaning (Wylson and Wylson, pg. 153154).

With the creation of a new theme park, it is also important to establish a cohesive theme, and determine how the design will support the theme.

For example, European themes at Busch Gardens and Europa Park create a particular national ambiance with the appropriate cuisine. At Asterix, a restaurant space is enclosed in a giant replica fruit and vegetables.... Similarly, show entertainment can be enclosed to give the appropriate ambiance. The entertainment area at Middle Kingdom, Hong Kong, is based on the Empress Theater of Beijing. The Oktoberfest at Busch Gardens conveys the Bavarian character. (Wylson and Wylson, pg 154)

Though the general design principles are the same in both scenic design and theme design, it is rare that the architecture of a theater can be changed in order to accommodate a scenic design, or that a location is being designed in order to house the production. In scenic design, there are set parameters that must be adhered to, based on the current existing structures that already exists in the theater. A designer for themed entertainment may only be in charge of fitting a new kiosk into a specific location and designing it to fit in with its surroundings, but it is also more frequent that the design of the park in general coincides with the design of themed attractions. In this way, the themed attractions' designs can affect the design of a theme park on a grander scale. With 
many theme parks expanding, it is also more likely that a themed attraction's design can influence the way in which a park expands. 


\title{
Chapter 5 \\ Objectives for Audience Effect
}

Both scenic design and theme design share the purpose of affecting an audience, but the techniques they use in order to get a specific reaction from the audience is different in each field. Theatrical design puts the audience outside of the action. The environment can be interactive to a point, and the audience may not strictly be looking into the front of the stage as in a proscenium, because of the prevalence of thrust stages and black boxes. However, regardless of the spatial configuration, the theatrical audience is being led through a journey created by a script or libretto (Rizvi), and a carefully cultivated picture is created to gain the desired audience effect. Because the audience is generally stationary, it is easier in theater to direct an audience's attention toward the specific item or moment that is necessary for the story to progress. The set can change to accommodate a new location, and the dialogue gives exposition so that the story is easy to follow. The set assists understanding of the action on stage, but it does not have to be literal in order to get the desired effect.

The scenic designer has leeway to create a set that does not have to be literal in all moments, and can use abstracted ideas and creative usage of props and scenic elements. The audience is willing to fill in the gaps, and a suspension of disbelief is assumed. Lighting can be used to set the mood or indicate a time of day, and the audience does not force a literal translation on to the stage.

\begin{abstract}
A blue light in film is a blue light, begging the question, why is it blue? 'What's out of frame creating that light?' A blue light in a stage play is often used to set a mood or a time of day. No one in the audience thinks, 'Mmm, where is that blue light coming from? Is there a cop car offstage?’ They see the light and automatically interpret as mood, or moonlight, or whatever it's meant to mean, due to their cultural training in theatre. (Otte)
\end{abstract}

While theatrical design allows for more abstraction and suspension of disbelief, themed design must take a more literal approach. There is no script that is providing additional exposition, and the audience is constantly moving, getting different views of your creation. A guest may only 
see a design for seconds or minutes, and it must convey its purpose and theme just as quickly (Rizvi).

The audience for themed entertainment is usually unaware that they are an audience in the first place, so what they see must create a reality for them.

"If there is meaning in the interpretation, it is done in a way that subtly affects them, often with them not even realizing they have been affected.” (Otte)

It is important to consider how a patron will interact with a display, storefront, or kiosk. The theme must be taken into consideration, and the design approached from all possible angles, all while trying to get in your guest's shoes as much as possible (Rizvi). Unlike in theater, every angle must be a finished product, with no unpainted backs of flats, or walls that are painted to look like brick, but have no dimensional texture. That is not to say that all materials used must be entirely real, with no faux finishes. In a theme park environment, it is important that all surfaces must be convincingly real to the audience, whether being examined up close, or seen quickly from a distance, such as a "brick wall” being created with a pattern of joint compound mixed with sawdust, arranged to look like bricks, instead of a wall being built out of bricks, or a flat surface being painted with trompe l'oeil. In a themed design, everything must be convincingly real to the audience, while theater has the luxury of suspension of disbelief. 


\section{Chapter 6 \\ Designer's Primary Focus: Aesthetics versus Construction}

Another difficulty that could be presumed when making the leap from scenic design for theater to themed entertainment design could be a change of priorities when it comes to aesthetics, construction, and function of scenic elements. As a scenic designer in theater, the primary focus is on the aesthetic features of the set, and its functionality, and emphasis on specific means of construction are determined by another member of the production team, the technical director. This is not to say that the scenic designer cannot have any say in how the set is constructed. It is not uncommon that a scenic designer drafts the set in a way that gives enough information that building can begin straight from the original drafting. However, it is more likely that the technical

director takes the original set of draftings from the scenic designer, and creates more detailed build drawings based on the original drafting plates. The scenic designer's primary focus is on the final product's appearance, and to inform the technical director what is important about a scenic element, so that it functions properly.

The scenic designer must also consider functionality of the scenic elements, for issues as small as which direction a door swings, to how large set pieces track on and off stage, or how the set revolves on a turn table. The scenic designer must determine how he would like to see the set function, and can make specific suggestions about how he would like to see it created, though it is up to the discretion of the technical director to actually create that functionality, and get as close as possible given the allotted budget, materials, and manpower available.

While in scenic design, the designer has the option of giving input about the specific means of construction, the involvement of the themed entertainment designer is more complicated. Based on interviews, the consensus is that it depends on the project. For Brian Barker, he finds that there is very little painting, and everything is much more heavily focused on printing when he has a commercial job. To that end, his graphic design and sign work become significantly more important, and must be polished from the beginning. Printing also effects exactly how something must be built.

In theater, you can build a flat out of fabric or wood, or the concrete back wall of the theater. As long as you get the same result as a painted surface, it doesn't 
matter what it's built out of. If you're printing, you have to be concerned about the surface it's mounted on. UV printing vs. dye sublimation, etc. Material choice and construction become a lot more important. DPI (resolution measured in dots per inch) is a big deal as well. It must be perfect everywhere, up close. (Barker)

For these projects, Barker takes special care to indicate exactly how a design must be put together in order to create the best product.

For her work with Busch Gardens, Batul Rizvi makes notes about how she would like an item constructed if the design and the construction are correlated. The production team that she works with determines the exact way that an item is built, and Rizvi does not determine the structural analysis of her designs, though she does call out segments that must appear to be more realistic. In this way, the production team can determine whether an item must be built out of the "real" material, or whether they must find a less expensive means of creating the faux finish, if painting is not adequate.

In the case of large-scale design with design firms, the design and construction process is phased. It is not uncommon that after the design phase is completed, there may be a re-bid for the next phase of construction, effectively separating the production team into wholly separate groups. Through the design phase, it is important to consider the feasibility of a project, especially because the contractors in charge of building the design are not necessarily included at this early stage. However, it is not the main consideration over design, and there are frequent changes to the plan. Budgets are ever evolving, and major budgetary changes can cause an entire project to be reconceptualized.

The first phase is almost smoke and mirrors. The schematic phase has more concrete budgets. We have to determine how we actually make this happen in the schematic phase. Is it going to be scenic, concrete, built to last with 100,000 guests, or a show on a stage? At the Smithsonian [a recent design project], everything has to be built like a rock. [There would be] tons of wear and tear on everything, which is a major driving force for design. (Otte) 
For both themed entertainment design and scenic design, the focus of the designer is primarily on the aesthetic qualities of the design, and the specifics about construction can vary based on the designer's preference, the way the production team works as a whole, and the specific project itself. In both design fields, certain projects will require the designer to be fully engaged and hands on throughout the entire build, while others will end a designer's involvement after final drawings are submitted. 


\section{Chapter 7}

\section{Observational versus Immersive Environments}

A major change in designing for theater versus themed entertainment is how the design is presented to the audience. Theater is presentational, and the audience is looking into the world on stage from the outside. There is a story that can be clearly followed, and exposition in dialogue and action, which is directing the audience's attention. The environment created by the scenic design only tells a fraction of the story, and has the support of other design mediums (lights, costumes, sound, etc.), as well as the script propelling the whole show forward. The audience is guided toward what we want them to pay closest attention to.

In Entertainment design, there is no way to force the audience to look at every element in an environment. The theme must be perfectly clear on first glance, because the attention may be fleeting. In the immersive experience of a theme park, the designer lacks control over the audience's attention, because it is more difficult to direct the audience's eye. Story, action, and light can be used to direct focus, but it is important that every part of the park be perfectly finished, because the audience has the freedom to come and go as they please.

"I'll prioritize where the main story beats are playing out, and focus on them first, providing the less active areas with less attention.” (Otte)

Another difficultly designing for an immersive environment is the lack of control over the elements. In theatrical design, the space is typically indoors, with very controlled lighting. The lighting designer creates a specific ambiance, and effects tailored to the action of the play, and the scenic elements on stage each moment. For themed entertainment, there are often indoor areas, which can have these advantages as well, but for outdoor theme parks, each design must be attractive in both daylight, and at night time when the only lighting may be artificial, and directly from the park. All attractions must be able to hold up in rain as well, leading to more sturdy construction to help with long-term wear and tear. (Rizvi)

The target demographic is an important consideration in themed design. In theater, the script can clarify who the audience will be, and the set does not have to clearly state the age or gender of that targeted audience. For theme park design, the scenic elements tell the story, and the 
target demographic must be clearly demonstrated. Take, for example, Universal Studios Islands of Adventure, in Orlando Florida. The theme park is broken into 6 areas: The Wizarding World of Harry Potter, Toon Lagoon, Marvel Superhero Island, The Lost Continent, Jurassic Park, and Seuss Landing. Each area has a very specific theme that reaches into all aspects of their rides, shops, restaurants, and common spaces. Seuss Landing in particular does a wonderful job at indicating the demographic they are catering too. Upon entering, the colors, shapes, and constant references to the children's books by Dr. Seuss, in everything from street signs to shop names, clearly indicate that this area is most appropriate for young children.

Walt Disney, arguably the creator of theme park design as we know it, clearly understood the necessity of clarity of theme in a fully immersive theme park environment. He developed several conventions that are still used in theme parks around the world, over 60 years after the opening of his first theme park, Disneyland, in Anaheim, California. He understood the shift from having an audience that is only viewing his films, to suddenly experiencing an environment in 360 degrees, and how to create a story, even without being able to direct the viewer's eye and present a script.

Instinctively, Walt Disney understood the communicative power of simplicity. He built the foundation of his company on visual story-telling. When he and Ub Iwerks started making motion pictures in the 1920's, they wanted to tell a complete story in their eight minutes or less of film time. To accomplish this, nothing could interfere with or stray from the idea or action they wished to communicate. Walt had a specific reason for doing everything he did. (Walt Disney Imagineering, pg. 90)

Much of Walt Disney's inspiration for a themed environment developed from what he had learned working in film. He determined how to adapt those ideas into something more applicable to the immersive environment of a theme park.

When it came time to enter the three dimensional world of entertainment, he brought the things he learned from film making to creating parks. A motion picture director has the luxury of creating an optical target—by placing action and focus or 
color. In a theme park, however, the viewer is not just an observer, but a participant. The imagery is not confined to the parameters of a movie screen, and the participant is bombarded with visual overload. The key to making this work is for each element to mesh with the story. When inventing the process of theme park design, Walt and his movie-markers-turned Imagineers converted many of their film-making principles into three-dimensional application. (Walt Disney Imagineering, pg. 90)

These concepts did not only apply to rides and sections of parks, but had to be carefully implemented in order to create seamless transitions between different sections of the park, which each had their own unique and diverse theme.

One such principle is the cross-dissolve. A stroll from Main Street to Adventureland is a relatively short distance, but one experiences an enormous change in theme and story. For the transition to be a smooth one, there is a gradual blending of themed architecture. Even the soles of your feet feel a change in the paving that explicitly tells you something new is on the horizon. Smell may also factor into a dimensional cross-dissolve. In a warm summer breeze, you may catch a whiff of sweet tropical flora and exotic spices as you enter Adventureland. Once all these changes are experienced, the cross-dissolve transition is complete. (Walt Disney Imagineering, pg. 90)

Designing for an immersive environment presents additional challenges not included in a theatrical setting. While in theater, an audience is seeing the set from one angle, and at a relatively great distance, the theme park visitor is up close and interacting with the architecture and installations surrounding them. Each item must be finished and highly durable to stand up to natural wear and tear, weather, and the constant interaction with guests, while a theater set must be convincing from only the angle at which the audience sits, and provide a safe space for the actors. A designer must relate the chosen theme in every unit within a themed environment, and find ways to hold the audience's focus without a script or action to give exposition. While the technical process of creating renderings and drafting may be very similar, there are a great many 
additional considerations that must be taken into account when the design itself must communicate the entirety of the story. 


\section{Chapter 8 \\ Research and Flexibility in Concept}

For theater and theme design, the overall objective in what you want the picture to say is driven by different forces. In theater, the script drives the design, and the script drives the research. Even so, the script can be interpreted in many different ways, and it is possible to see the same show performed in a myriad of different ways, in different styles, with completely different designs. A director or designer may strive to bring out a message in the play that is rarely highlighted, and that could drive the design. Ultimately, there is a great amount of flexibility in the driving concept behind a play's design, and that starts with the research. A scenic design can start with research based on an emotional response, and develops through discussion with the

director or production team. For theater, a design can start with the designer going to the library or searching online to find pictures that resonate, and then building off of them through reactions from the director (Barker). The design can be very literal, based on specific period décor and architecture, building what appears to be an actual living room on stage. On the other hand, it can be completely abstract, with unrecognizable structures doubling as a chair, a bed, a swing, and anything else, all in one play. There is significant creative freedom in theatrical design.

For commercial design, there is more rigidity in what is possible. There is a style guide that's been developed with graphic looks, and specific branding that must be adhered to (Barker).

In 2010, there was a place in Mets Stadium called “Verizon Studio,” with consumer engagements, like Verizon jerseys and autographed baseballs you could "text to win." We designed that space, and lot of that was really weird because it was creating a Verizon/Mets cohesive space with their separate style guides, to converge and integrate those two things. Some clients, like Nickelodeon, they create a different style guide every week. A lot is just about understanding the brand, and how to create graphics, spaces, and shapes based on the brand, so the whole thing feels cohesive. (Barker)

Batul Rizvi has had a similar experience working with Busch Gardens. Different installations have different design needs, and her research is adjusted accordingly. For the Food and Wine 
Festival, for example, the kiosks are based on different cultures, and give guests the opportunity to experience décor, food, and drink from different countries and states. She is able to take creative liberty on the actual design, but everything must be rooted in clear and accurate information about the culture at hand. There must be much more specific care taken in researching to represent such an important topic. For other installations, such as a promotion for a new Howl-O-Scream maze, the research must be strictly related to the maze's already created premise. There are already branding guides specified by SeaWorld creative, and explicit thematic elements that must be highlighted, as specified by Busch Gardens. In general, it is mix of her own inspirational research, and SeaWorld's branding guides that cultivate the design. This process holds some similarities to theatrical design, but the incorporation of specific guidelines does complicate the process.

In theatrical design, it's all about original research and taking ideas where you can get them. You don't really have a company telling you what fonts, logos, colors, and themes to incorporate into a design. I think in corporate design, you have more people to satisfy, and in theater, you have your director and creative team to collaborate with—but in the end, your audience is your main clientele—so you can get away with a lot more. (Rizvi)

When it comes to specific rides, often the world in which the research must come from already exists. Many of the rides and attractions in the Disney theme parks are three-dimensional creations based on an already established canon from one of their films.

In rides like Snow White’s Adventures, Peter Pan's Flight, or Dumbo the Flying Elephant, the characters are the same as those already established in film, and therefore instantly recognized and accepted in a three-dimensional role. At the same time, they bring to the ride a "built-in" mythology and design theme based upon the story developed at length in their respective films... But when characters are exclusive to a theme park ride or show, they must be able to effectively represent a theme and tell the stories of their attractions in no time at all. (Walt Disney Imagineering, pg. 44) 
Many attractions are based on an already existing character or film, while others can be formed around new characters. The ‘Pirates of the Caribbean’ ride, for instance, is a rail controlled boat ride, which takes guests through stages filled with animatronic figures, telling a story from beginning to end. In essence, the ride creates a short film that the audience is immersed in (that is, before the ride was adapted to be a feature film).

[Pirates of the Caribbean] is, in effect, a journey into a Disney film. In each case the buildings have an impressive point of entry appropriate to a theme, and a large enclosed activity space or studio behind. The movement through the space is at various levels with a commentary, background music, or voices from the animated figures, and lighting effects to dramatize the experience. (Wylson, pg. 49)

It is important that a theme presents a strong unity of concept, and that puts limitations on the direction research can go. However, according to Charlie Otte, his research still remains fairly broad at the beginning of any project. Whether for theater or entertainment, he finds that image research has become so easy to come by, that getting enough research is never a problem. He instead puts value on being able to cull down the amount of research that seems relevant, and hone in on his (or another designer's) aesthetic and style, to focus in on the specific needs of a project without getting bogged down with too many "good" ideas.

There are always weird gems that can surprise you and be interesting. You have to preserve your originality, and not become purely derivative... For instance, the Fast and Furious [sic] press event, for the tram tour at universal, I just watched the fast and furious movies [for the first time] to get a sense of what those were about, to get a sense of what the ride was about, and then we distilled it down to a couple of pitches that we gave to them. It came down to cars and girls, and I said "Okay, we could do a big stunt show with cars and things flying through the air." That's the one we kind of kept coming back to. It's kind of what we ended up with, and it turned out great. It was a huge success. (Otte) 
Otte's research for the Fast and the Furious press event revolved around digging into the original film, determining the most important and exciting features, and developing a way to create a new event in support of that theme. There is little interpretation or discussion about a deeper meaning, or bringing anything experimental to the design. For themed design, it is important to be able to whittle down the research and the ideas to what is most essential, without getting bogged down with an excess of potential directions.

What happens is the ability to have too much can paralyze some of these larger groups sometimes, and keeping yourself on task and focused is a big part of the job. It's easy for people to second guess themselves. There's a lot of pressure, and everybody always feels like their job is on the line. These particular events, we were hired to do them, as opposed to work with an in house team. They could go to their boss if it was a success, but they could point the finger if it failed. (Otte)

For themed entertainment design, the original source material provides the pool that research can be derived from in its entirety. In theatrical design, there are many directions that research can go, but themed entertainment has more restrictions. It depends on the specific project, but whether the installation is based on a specific culture, or an already beloved film, the research must not veer in a direction that would conflict in any way with the original source material. There is little flexibility in concept for themed entertainment, because cohesion and strength of theme is so vital to the audience experience. 


\section{Chapter 9}

\section{Collaboration and Hierarchy}

Division of power and the hierarchy within a company can vary greatly through different design fields, and from production to production. There is such a high degree of collaboration in theater that makes it difficult to see where collaboration ends, and a boss-employee relationship begins. In general for a theatrical setting, the director leads the discussion, and is the "boss" of the production. The scenic designer answers to the director, and works in collaboration with the director (and other designers in costumes, lights, etc.) to create a design that works cohesively with the play. The scenic charge, technical director, and props master generally answer to the scenic designer, while the props master and scenic charge also answer to the technical director on more functional demands, construction, and scheduling.

Though there is some clarity in hierarchy in production staff (the people that build, paint, cable, and create the final product), compared to design staff (the people who design the various material involved in a show), the collaboration among the design team is less clearly defined. For a show to be successful, everything is highly collaborative, and a design grows through meetings discussing the intention and meaning of the play. The design changes based on feedback from the director, producer, technical director, and other designers. The scenic design must work in harmony with the lighting, costumes, sound, projections, props, special effects, music, acting style, etc. While collaboration is important, the scenic designer's realm of influence can sometimes extend further than the actual set. The scenic designer is generally the top billed designer in the theater, and because of build time, and lack of actor involvement (as opposed to costume design,

where it is important to know how a show is cast and who the actors are), the set is typically the first part of a show to have a completed design. Because of this, the set design has greater influence on the other areas of design than vice versa. The scenic designer's realm of influence extends most clearly into properties design, special effects, and projections. The props master may be given a significant amount of design control over what props are put on stage, but it is part of the scenic designer's job to provide research images, drafting, or a location to purchase important props and furniture, and to give the final approval of props. Projection designers are fairly new in theater, and there is not a clear-cut division of labor. The projection designer is in charge of creating content, and working with the equipment, while the scenic designer may have influence 
over what the content is going to be. The scenic designer chooses the materials used, and the surface on which the projections will appear, though insight from the projections designer may be useful in order to create the most satisfying product.

Costumes and Lighting are minimally influenced by the scenic designer's opinions, other than in color palette coordination. The costumes are largely unaffected beyond color palette, which is decided during design meetings, before any construction begins. Once the costumes are built, the scenic designer does not have influence on further changes to the costumes, or vice versa. Lighting, on the other hand, has a very clear effect on how the set appears to the audience. The scenic designer can make suggestions and request particular colors of light be used in order to best present the set. However, the lighting designer has the final say, and these requests are best made early the process, to facilitate productive collaboration.

Like theater, themed entertainment design is quite collaborative, though in a less clearly defined way. While a theatrical production has very specific designer roles, the themed entertainment collaboration is based more on the needs of the client, the ideas of the designers, and the opinions of a creative team that can consist of many different types of experts.

The design team may include architects, designers, project management consultants, engineers, quantity surveyors, as well as a specialist consultants (safety officer, zoologist, marine biologists, landscape designer, historian, graphics, and audio-visual creative designer) and special suppliers. (Wylson and Wylson, Pg. 152)

The themed entertainment designer can often have more control of elements that impact the design (lighting, sound, digital media, etc.), unlike in theater where that control is limited due to highly specified areas of design. In her work at Busch Gardens, Rizvi notes that she does have control beyond the scenic elements, but that even with her influence reaching beyond, each decision is still very collaborative.

When it comes to a look, everything like lighting/sound/special effects falls under it. Although I don't have a say in the specific gels or beam angles used in the lighting of a merchandise kiosk or performance stage, I could have a say in the overall 
feeling of the product (warm lighting, make sure stage left is lit, lights resemble skulls instead of Lekos, etc) which I would just call out in a design package and discuss with the appropriate supervisor of the department. I would say it's less about control over a project detail and more about collaboration with departments to get a concise look across the board. (Rizvi)

Brian Barker's experience has been much the same as Rizvi's, in that he does have more control of lighting in particular, when it comes to corporate installations over theater. For the Verizon Studios project in Mets Stadium, Barker laid out the specific requirements for lighting, as well as for a project designing a visitor center for West Virginia University. A lead architect was available to check on specific wiring, and ensure everything was properly installed, but Barker chose where and how to integrate LED's into the design, and where to place lighting fixtures to properly display the exhibits.

Charlie Otte insists that the designers for themed entertainment can have more influence than some of the collaborators ranked highest on a project, such as the project manager or the artistic director. Though this can be dependent on the size of a project, and the size of the creative team, a designer in themed entertainment can have a strong influence on all aspects of the final product.

When you go to a big park, the design is what's telling the story. Quite often, designers are in a position of authority, able to make decisions at a much higher level than they would be at the theater. There's a guy I worked with on the Lincoln Presidential Library, he laid out the whole way you were going to walk through the exhibition, through Lincoln's life. As the creative director, I was in charge of the whole thing, but because his work was so important, he kind of was able to take it and run with it. He is now one of the creative heads at Universal Orlando. (Otte)

While collaboration is still necessary in themed entertainment, there is not much designerto-designer collaboration. There is a strong, though not always clear, chain of command, and a scenic or theme designer may be the only designer within the creative team, unlike a theatrical production that has many designers from different disciplines represented. 
For a lot of what I do, there’s project managers, client managers, account managers, someone who finds the designer, and finds everyone to facilitate the execution. Usually I report or answer to an account manager or client relations manager. There are different titles for different places. (Barker)

Barker often works as the sole designer on projects, but he has worked in parallel with other designers. Typically the responsibilities are divvied up, with Barker, for instance, designing the structures, while another designer works on graphics. Rizvi has had a similar experience, as she is the only official designer of Williamsburg Busch Gardens.

There are parallels of my position at SeaWorld and Busch Gardens Tampa, and sometimes we talk to bounce ideas off each other, but that's about it. As far as in the park, when I'm being given a design - the others in the entertainment department are also the creative team and they have an idea of the end product, but they just don't know what exactly they want, which is where I come in. Every project has collaboration because everyone has input on the design. (Rizvi)

Though there is only one designer within the park, Rizvi explains that there is no clear chain of command, because her job is so varied. As the sole designer, Rizvi works with many different departments, such as Park Operations, Culinary, Merchandise, Marketing, Landscaping, Entertainment, etc. While she has a direct supervisor that handles her timesheet and basic company needs, her "boss” from project to project changes based on the department handling the project.

If it's a show product, (like a promotional design for Celtic Fyre, one of the mainstage shows), I'll go to the show team and project manager for notes. If it's an event product (like a Christmastown photo op), I'll go to the event team and project manager for notes. Bottom line, it's the person who gives me the task that I go to for notes. As far as implementation, there's theatrical services and entertainment services and also park carpenters and painters, and it just varies who I directly work with based on the project it is. (Rizvi) 
Charlie Otte is usually in the position of creative director or senior creative director in his work in theme design. In his experience, there is rarely a linear chain of command.

\begin{abstract}
You always have a client, you're always dancing around them. I'm a creative director or senior creative director, so I'm relatively high up the food chain. I work with the producer to make sure we're answering the needs of the client. Sometimes we have to be aware of internal company politics for corporate jobs. There's a creative director, producer, production designer, architect; you're all working together closely. Then there are going to be, beneath that level, researchers, props people, art directors, people doing drafting, people doing specific artwork, editors, writers, production management, production coordination, etc. In a creative environment, it's tough to say you answer to this specific person. You generally answer to the production manager. What's best is a strong team where hierarchy is implied, but not beating down on anyone’s heads. (Otte)
\end{abstract}

While theatrical hierarchy is similar in most theaters, the chain of command in themed entertainment is more amorphous, and changes from project to project. It is rare that a designer has to work in parallel with someone in the same role, though it is more common for designers to work together towards a cohesive goal, while taking care of different aspects of the design for larger projects. As a designer for themed entertainment, it is necessary to be able to articulate the needs of an installation beyond the typical components considered by a scenic designer, whether that be lighting, digital media, special effects, etc. 


\section{Chapter 10}

\section{Presentation of Design Concepts}

A potential difference in a designer's role for scenic design vs. themed entertainment, is how to communicate the final design with the client or producing organization. For theater, there can be many different things expected, depending on the director's needs, and the complexity of the design, but generally it comes down to a drafting package, a paint elevation package, and some version of a model. The drafting package could be highly detailed, so that a carpenter could begin building straight from those plates, or it can be just detailed enough that the technical director has a clear picture of what must be constructed, so that he can create technical drawings from the drafting package. The paint elevation package will include colored rendering of every item in the show that receives a paint treatment. These renderings could be fully digital, made from Photoshop, SketchUp, Vectorworks Renderworks, etc, or they could be hand painted, or a mixture of both mediums. The model may also be either fully digital, through programs such as Vectorworks or SketchUp, or could be a physical hand-made model. 3D printing is also a relatively new option that can assist with building a physical model. Whether a digital or physical model is created often depends on the needs of the director, as well as whether there is any traveling involved for the designer. Physical models have the advantage of helping to visualize the setting more easily, though digital models are quicker to build and adjust, and can be sent easily through email cross-country if necessary. A scenic designer may have to provide additional paperwork for a show, depending on the complexity. For a set with many moving pieces, storyboarding may be important, and providing groundplans for each set adjustment, complete with how scenic elements will be stored off-stage, is essential.

As with many other qualities between these two design mediums, while scenic design has a relatively straightforward set of needs when presenting the final design, themed entertainment is less clear. Batul Rizvi has had much fluctuation between what is necessary, and what seems appropriate based on the individual project needs.

I sometimes compile everything (including scans of original sketches) into a PowerPoint to present in a meeting, and then make sure everything is in PDF so I can just email everyone in the company involved with the design. It's then 
uploaded onto a company server so those who need it can access it at their convenience. (Rizvi)

Rizvi has standardized her way of presenting her design package, but the tools she uses to create her design vary, which creates less consistency in the details of the design package. Rizvi sometimes uses hand sketches and watercolors, while other times she primarily sticks with Photoshop. Sometimes orthographic projections, specific detail views, ground plans, and 3D composite views showing how an installation fits into the park, become necessary to make her intention clear. 


\section{Chapter 11}

\section{Moving Forward After a Design Concept is Accepted}

In both theater and themed entertainment design, there is an initial planning period where designs are formulated, adapted, and developed, before they are accepted to move forward. For scenic design in the theater, the designer leaves the initial planning period (design meetings and discussions with collaborators involved in the project), and creates a comprehensive drafting package, which can be passed on to the technical director. From that point on, the technical director can create technical drawings and manage the build, keeping in mind the schedule, budgets, and staffing needs. The scenic designer has periodic check ins with the technical staff to discuss progress, difficulties, or necessary adjustments to be made for construction, paint, props, projection, special effects, etc.

A themed entertainment designer may not have as clear-cut a path when it comes to finishing their design packet. For theater, the material produced by the designer depends on the designer's strengths and personal preference, whereas in theme design, the material produced depends on the client. In Brian Barker's experience, the client can vary from being quick to micromanage every step, wanting a say in every minor tweak to the design, to clients that present the project, approve the initial concept, and have no interest in seeing anything until there is a final polished rendering and drafting package.

It depends on the client. I have some clients who want to micromanage my breathing. It's terrible, and I don't like working like that.... Some people I work for, here's the project, here's the deadline, here's a rough budget, just keep it under control. Let's see the plans and some thoughts and scribbles, and they're okay with it. Unless it's a good sales tool, they don't want to send anything to the client that's rough. You're designing so that people can take it to their boss and get their boss to sign on, so that they can do the project and add value to the company. (Barker)

Rizvi agrees that the particular client (in her case, the department presenting the project to her) drives what materials she produces for each project. 
It does depend on the type of design and more importantly, who gives me my project assignment, and what they ask for. Some clients will specifically ask for a mockup of my design, and some clients will just want a design package. Either way, what I've learned is that there will be notes and revisions either way, so a final package separate from a first revision is to be expected. (Rizvi)

As Rizvi mentioned, revisions are a necessary and expected part of the design process. In Otte's experience, revisions can happen at any point in the design or construction process, and a design firm may be liable for any changes. In order to protect themselves, it is important for designers to continue to meet with the client, and consistently ask questions, and indicate conditions that have been met.

You'll set up a series of meetings in advance. In one of these companies, you need to get them to sign off at repeated points, because half way through they could start changing their mind, and depending on how the contract was built, your company could be liable for it. So you want to set up meetings, and in those meetings, be able to present very distinct, bullet point landmarks that have been met and signed off on. It's important to keep them engaged, and the client feeling like there's ownership, and determine what they really want. Filter what they say, and understand that there's a certain psychological game you play; why do they want that, what do they mean? In theater, you have to read the script, listen to the director, they say they want all these things, or they just want something that gives them the feeling behind what they just described to you. It's important to be able to discern the client's real wishes. (Otte)

Unlike theater, where a hard deadline is fast approaching, themed design can often have a less rigid end point, or a lengthy design process, which can lead to clients (sometimes due to unfamiliarity with the design process) to feel comfortable making huge changes, or asking for entirely new ideas late in the process. It is important to try to interpret what a client means, beyond what they are saying on a literal level, in order to prevent a sudden need to change direction. 
I had a client that we worked with doing a piece in Jordan, and I mean literally every meeting (I've had many clients like this, who are just moving targets), the next meeting's different. You can keep trying to accommodate a client, and at some point it starts to impact the work, and impact the money. Disney is notorious for this, spending months and months on a project, it goes up the hierarchy, and then they decide they don't want it. Communication is always very tricky. Your client is actually a producer who is in the parks. There's an entirely good chance that that producer came up through retail, so their take is 'What's a show that sells product?' But not understanding that, what sold that merchandise in the first place, was the story and the interactions. So it's always really important to get into the head of the person you're working with. (Otte)

Themed entertainment design has a less clear-cut path that the build takes, once a design is approved for production. In Brian Barker's experience, his involvement beyond the initial planning can vary to extremes.

Sometimes we'll have a shop hired; I'll design stuff, then it's been built and I'll never see the end result. They just send me pictures of the installation, and we have phone conferences. [For one project] I have yet to see the client who paid me. It's been open for two years! But the last project I did was built fairly locally. I would go to the shop in Richmond, give them notes, and sometimes even build myself. I'll usually send things off to have them CNC'd [Computer Numerical Controlled Routing, used for cutting numerous hard materials with extreme precision]. It's a little more like technical direction sometimes. (Barker)

In Rizvi’s work with Busch Gardens, she has a very different experience. After a project moves from her hands into construction, she has little to do with execution.

I check in periodically with the execution and give notes if I have them. Sometimes, the contracting company or engineering department will run their technical 
drawings by me first, but that'll be the extent to how much I deal with the actual construction. (Rizvi)

Otte has a similar experience, but says that he considers his role to change to a more supervisory position, because of how the construction proceeds.

There's usually a technical director or company that's building things, so you might be able to go in and do some final painting, but even then, at a certain level, like with a large corporate job, there's a big scenic company doing the build and overseeing the building/painting. You may be at the shop just making sure they're doing it right, or at installation, making sure it's being installed properly. It's more supervisory. (Otte)

Otte does mention that as a younger designer, that was not always the way his role progressed.

As you're coming up the ranks though, doing smaller theater, you may be designing and building. In my case, designing, and hanging the lights and programming, creating, shooting and editing the media—at a certain point you are able to oversee that work. (Otte)

While the process of designing for a theatrical production is relatively streamlined, designing for a themed entertainment installation can be more uncertain, and much depends on the specific client. There are potentially more barriers to getting a design finalized, due to the number of people's needs that must be addressed, and often because of the significant number of people involved in decision making, who have little experience with design or production, and may have very different backgrounds. 


\section{Chapter 12 \\ Budget Consideration}

In all areas of entertainment design, budget has to be a factor when it comes to design. Whether a budget is completely rigid, or could potentially grow due to more funding or additional investors stepping in, depends on the project. In scenic design for theater, the designer is aware of the budget, though rarely is he the one making purchases and determining exactly how a budget will be spent. The scenic designer must be cognizant of the budget, in order to design a set appropriate in size and complexity. The details of the budget are not of concern until the design is more fleshed out, at which point the technical director may step in to bring up budgetary concerns. The technical director is in charge of taking the scenic designer's drafting and renderings, and determining how a set will be constructed, taking into account the already established budget. If a design is doable with the allotted budget, the technical director moves forward determining the details of construction. If the scenic design does not seem realistic with the allotted budget, the technical director will converse with the designer to discuss adjustments to cut cost. It is important that the designer be firm in what they consider to be important to a design, but be flexible in this process, so that the design maintain its character and functionality, without losing too much when there are necessary cuts. Additional budgetary concerns other than the materials themselves are related to labor. For many theaters, mostly small educational or regional theaters, the scenic elements are built in house, with a small crew, and a fluctuating amount of over-hire, depending on the size of the theater's permanent staff. Larger theaters, such as commercial theaters and Broadway theaters, have larger budgets, and send the designs to professional scene shops. Professional scene shops have higher overhead costs, and so a design sent to a professional scene shop would be significantly more expensive than a design built in house.

The cost of a scenic installation in theater will generally be significantly less than the equivalent in a commercial setting for themed installations. According to Barker, the cost difference is massive.

Things in the theater world would cost $\$ 5,000$ for a set. Commercial world, you spend 3-5 times as much because of overhead, labor, markup, etc. If you called a commercial shop and said "I want you to buy the standard choir platforms," there’s 
a $20 \%$ markup. Everything is just so much more expensive, so the budgets are strange to get used to. A huge budget feels so easy, but as soon as a shop gets their hands on it, it all goes away. (Barker)

While Barker has to keep budget in mind for his commercial jobs, he generally has to keep his designs on the less expensive side, to make up for overhead costs. Though Barker does keep his budget in mind from the beginning of a commercial project, Rizvi tried not to dwell on budget early on. Though her initial design ideas are not changed by the budget allotted, she does have to do much of her own research sourcing materials that could be used in her designs.

I don't start designing a project with a budget in mind. Sometimes the execution team or the director of entertainment will ask for a "sourcing package," which just outlines specific products I would like, how much they cost, and from where they can be purchased from. Most of the time, I will send that information out with the design package, and they order products according to their budget. The team executing the project usually has specific vendors they order from, so they will try to get similar products to what I specify from there.

One of the changes Rizvi has mentioned between theater and themed design, is how much of the budget is going towards building, versus purchasing pre-fabricated products. The focus shifts toward purchasing a fully built object or decoration, because of speed and ease, as long as it will fit within the budget, instead of potentially saving some money, but having to spend the time building that same object.

I think this is where it differs from theater a lot. I was so used to having a technical director to budget everything and get my design executed in whatever way possible. In entertainment, they tend to focus on pre-fabricated products to purchase for photo ops, restaurant theming, seasonal decoration around the park, etc. It becomes the designer's job to figure out what products would work. For more permanent installations around the park and theatrical shows, there is a technical director role 
(although not technically called a technical director), who will budget and fabricate based on the design, more similar to theater. (Rizvi)

Charlie Otte, on the other hand, concerns himself with budgets mainly as a protective measure. If there is a very rigid budget, it is important to be as transparent as possible with the client and producer, and create checkpoints that the producer will sign off on, so that expectations do not change so drastically that the budget cannot cover the new expectations.

I only have to concern myself with budgets-for instance, the Smithsonian project — when there's a fixed budget. We had to be very clear about the costs, and the producer would inevitably inflate things. I have to be aware of the budget just to keep the producer aware. (Otte)

While budgetary concerns are important to keep in mind, depending on the project, they are rarely at the forefront of a designer's concerns, in both theater and themed entertainment design. Transparency and flexibility is important, but the aesthetics and functionality of a design should be a designer's primary concern. 


\section{Chapter 13}

\section{Timeframe Considerations}

The amount of time allotted to a particular project significantly affects the final product. In theater, this final product is rarely a permanent installation, and the time frame reflects that in its brevity. The specific amount of time allotted depends on the type of theater. For a typical summer stock theater, 3-6 shows are produced in a 2-3 month period. Multiple shows are being built simultaneously, and turnover between shows is very quick. Builds can be as short as two weeks, while overlapping another show's build with the same crew. Designs could be given several months to only a week to come to fruition, depending on when the designer is hired. For companies that function year round, and build in-house, builds can range from 2-8 weeks. Designs could be developed from a couple weeks to a few months, again, depending on when the designer is brought in. For commercial theater, such as Broadway, set pieces are often built at a professional scene shop that caters to large scale, long lasting scenery, that can manage to stay functional for months or multi-year runs. The time frames are more drawn out, due to the expense, the need for high quality long lasting work, and the off-site construction.

For themed entertainment design, the time frames are inconsistent, and the amount of time for designing versus building may be wildly disproportionate. With Brian Baker's work with Nickelodeon, he has been given nearly 7 months to produce the design material, followed by a 68 week build. However, in more recent work with Nickelodeon, he has been contracted with 8 weeks to fully design and build all of the material. The time frame varies greatly from project to project.

Sometimes you're given plenty of time, and it's still not enough time, and sometimes you're given no time, and it's actually plenty. Right now I am working on a rock concert that won't even launch until September [8 months from the time of interview]. (Barker)

As the in-house designer for Busch Gardens Williamsburg, Rizvi’s time spent on a project can go well past the design's execution and installation. Notes on current installations are a possibility, so adjustments on designs already in the park is a possibility. 
Although a lot of projects can be anticipated early because of the strict opening dates we have for events in the park, there can always be follow up projects that I'd be working on days before they would need it to execute the design.... A design never truly leaves my hands until it's struck here, there can always be notes on it or improvements to be made. Typically when given a design project, I ask for a rough date they'd like to see a first revision package. From there, a final package deadline is made after other departments get involved with their budgetary concerns and implementation needs. After I've submitted the final package, I do periodic checkins during execution to give notes or clarification and then archive the design accordingly. (Rizvi)

Rizvi's timeframe is always tied to the specifics of each project, so there is significant variation.

Some of that process can take months or weeks, it just depends on the scale of the project, how many departments are involved, and how permanent the installation will be. They typically tend to take more time with the design process on projects that will be in the park longer. (Rizvi)

Charlie Otte agrees that even for more large scale projects that he has worked on through design firms in California, the allotted time frame for designing and building could vary greatly. For large scale installations or promotions, such as theme parks or museums, the projects are phased. There is a concept phase, followed by a schematic phase. The concept phase is about brainstorming and creating the design material, while the schematic phase is about drafting and building.

Concept phase for a 1 year project could be six weeks. At the end of that, you want to be clear enough that the schematics are clear, then detail design, and if things start to change then, things become very expensive. You've already drawn, already bid, etc. (Otte) 
The general layout of a project may be determined by a number of factors. It is not uncommon for a design to include creating the space in which the show or installation will reside, which creates an additional set of problems, and a greater distance the budget has to stretch.

The facility has a certain set of requirements. The show has its own set of requirements. There was a show I did in Texas, where I designed the show and the theater, so at the end of the schematic phase, we have this great theater, but we are out of money before designing the show. If you have a flying drop, you're also designing that there's a fly system [in the theater], and how does that fly system work? There are a lot of interrelated elements. You'll end up with an architect wanting to put a duct system in a fly loft, [for instance,] and there's a lot of back and forth. If I'm the creative director, I'll see it through to the end. As show designer, I come in after the concept is nailed down, work through schematic, then turn it over to a team of drafters. For a one year build, for instance, there would be six weeks on a concept, three to four months on design and proof of concept, four months of build, two months of install, and then three weeks of tech. (Otte)

The time frame of a project varies greatly from project to project in the world of themed entertainment design. There could be as little as a few days to complete a design in order to send it into construction, or it could be several months of determining the scope of the project, and coming to a completed design before sending the material to draftsmen. The time frame depends on the budget, the scale of the project, and the total amount of time available before a project must go live. Unlike theater, which may have some variation, but has a general set of guidelines that a production's time frame may follow, there is no standard that themed entertainment design follows. 


\section{Conclusion}

Scenic Design for theater shares much in common with themed entertainment design, though there are clear differences, mainly due to structuring of a project and the varying scale. Many themed entertainment designers begin their career working in theater, and use their formal training in theatrical design to inform their choices when it comes to theme design. Much of the terminology and tools are similar, which leads to a final product that is driven more by the aesthetic qualities, and is more design-driven than a theatrical production, which has the support and exposition from action, dialogue, and other design elements.

There is much overlap in the tools necessary to complete design work within each field, with both using computer-drafting programs such as AutoCAD and Vectorworks, as well as digital rendering software and Photoshop. Because of the larger scale, and the need for a more sophisticated final product, themed entertainment design often requires more detailed animation software, as well as powerful graphic design software, on top of the programs used in both fields. For larger design firms and in-house designers for theme parks, these programs are often provided by the employer, though designers in both themed entertainment and scenic design are largely expected to have the basic rendering and drafting software when working in a freelancing capacity.

There are many design considerations that do not exist in theater that must be taken into account when designing for themed entertainment. The audience is placed in a fully immersive environment, and it takes careful consideration to find a way to direct the audience's eye. Everything visible must be completely finished and built in a way that will be long lasting and have structural integrity, while a theatrical set must be convincing from a distance, and the action directs the audience's eye to wherever is the desired focus. In a drama, the audience is aware that they are observers, and there is an assumed suspension of disbelief that facilitates the presence of mood lighting, moving sets, and abstracted elements on stage being believable as representative of other objects. For a theme park, where the audience doesn't have a clear point on which to focus, it is the designer's job to create a seamless environment with a clear theme that tells a story, leaving no corner un-treated, so that every audience member gets a clear picture and a full understanding of the story the theme tells, from any perspective.

Another clear difference between these two entertainment mediums is the flexibility of concept and the source of research. The drama has few restrictions, and endless possibilities for 
visual interpretation; but ultimately, the scenic design supports the action and the script. The scenic design for any play can go in many directions, but it is rarely the focus. In themed entertainment design, there is less freedom to go in any direction that the designers may desire but, conversely, the final product is driven by aesthetic interests, instead of a narrative: the product is not just a supporting player, but rather the entire attraction.

Beyond the initial design phase of a project, learning the hierarchy and moving forward with construction can vary greatly from theater to theater, and between themed entertainment design projects. The amount of involvement in construction and production in both mediums can vary greatly depending on the budgets, the time frame, and the original contracts. Budgets and timeframes can differ immensely from project to project, and the hierarchical structure changes depending on the project, design firm, or client. The division of power tends to be more streamlined within the theatrical community than through the entertainment design industry.

While these two fields have many similarities that make a transition from one to the other a realistic endeavor, knowing the differences in the fields are crucial to determine which medium is a better fit, based on where your priorities lie. Themed entertainment design is a growing industry, which has recently been gaining traction as its own profession with MFA and BA programs across the country being created specifically to cater to its unique needs. The field can often allow for designs on a much larger scale than in theater, as well as more consistent and higher pay, though it has its drawbacks. While there are clear advantages to working in themed entertainment, the contracts often take away a significant amount of ownership over designs, and there is less recognition, compared to in a theatrical setting, where the name of the designer is in the playbill, and the design is considered intellectual property of the designer, not the theater. There is also a specific set of information and more rigid regulations on what materials can be used in order to keep within the subject's canon for a themed design, while theater allows for a much more abstract approach, because of support from other elements in the drama. Both fields have their positives and drawbacks, and personal preference and the designer's specific values, as opposed to skillset, determines whether a transition from theater to themed entertainment is right for a designer. 


\section{Works Cited}

Walt Disney Imagineering: A Behind the Dreams Look at Making the Magic Real. New York: Hyperion, 1996. Print

Wylson, Anthony, and Patricia Wylson. Theme Parks, Leisure Centres, Zoos and Aquaria. Harlow, Essex: Longman;, 1994. Print.

Wyson, Anthony. Design for Leisure Entertainment. London: Newnes-Butterworths, 1980. Print

Barker, Brian. Personal interview. 19 Jan. 2016.

Rizvi, Batul. E-mail interview. 14 Jan. 2016.

Otte, Charlie. Telephone interview. 20 Jan. 2016 